\title{
Adherence to combination therapy among ethnic Chinese patients: a cohort study
}

\author{
Martin CS Wong, Johnny Y Jiang and Sian M Griffiths
}

Discontinuation of antihypertensive combination therapy imposes a substantial public health burden, but few studies have addressed the factors associated with their discontinuation in Chinese patients. This study evaluated the association between patient age, gender, and number of comorbidities with discontinuation of combination therapies. From clinical databases, we included all adult patients prescribed an antihypertensive fixed-dose combination therapy during January 2004 to June 2007 in any government primary care clinics in one large Territory of Hong Kong. We studied the factors associated with drug discontinuation within 180 days after the first prescription date by multivariable regression analysis, controlling for age, gender, socioeconomic status, service setting, district of residence, visit types (new vs. follow-up), and the number of comorbidities. From 29253 eligible patients, $7.1 \%$ discontinued their antihypertensive prescriptions. Younger ( $<50$ years; adjusted odds ratios [aOR]: $0.78,95 \%$ confidence interval [Cl]: 0.66-0.92 for patients aged 50-59 years, $P=0.003 ;$ aOR: $0.71,95 \% \mathrm{Cl}: 0.60-$ 0.84 for patients aged $60-69$ years, $P<0.001$ ) and male patients (aOR: $1.19,95 \% \mathrm{Cl}: 1.08-1.31, P<0.001$ ) were more likely to have drug discontinuation. Patients with one (aOR: $0.64,95 \% \mathrm{Cl}: 0.57-0.73, P<0.001)$ and at least two (aOR: 0.68 , 95\% Cl: $0.54-0.87, P=0.002)$ comorbidities were less likely to have their medications discontinued. Combination therapies in Chinese patients had a low discontinuation rate when compared with Caucasian patients. Discontinuation was more likely among younger, male patients and those without concomitant comorbidities, in which more meticulous monitoring of their adherence patterns was needed.

Hypertension Research (2010) 33, 416-421; doi:10.1038/hr.2009.229; published online 29 January 2010

Keywords: antihypertensive drugs; associated factors; combination therapy; Chinese; discontinuation

\section{INTRODUCTION}

It has been well recognized that patient persistence to antihypertensive medications is a major component of hypertension management. Higher levels of adherence lead to lower cardiovascular morbidity and mortality, ${ }^{1}$ reduced health care usage, ${ }^{2-5}$ and hospitalization rates. ${ }^{3} \mathrm{~A}$ recent study reported that lower adherence to antihypertensive therapy was associated with a $38 \%$ increased risk of acute cardiovascular events. ${ }^{6}$ However, hypertension still remained poorly controlled in $>70 \%$ of patients worldwide, ${ }^{7}$ and recent reports suggested that approximately $20 \%$ of patients completely discontinued their antihypertensive treatment within 1 year. ${ }^{8}$

Fixed-dose combination therapies, defined as combination in a single tablet of low doses of antihypertensive agents whose mechanism of action is complementary, are an efficacious, safe, and cost-effective method of decreasing blood pressure in most patients with essential hypertension. ${ }^{9}$ Recent studies have shown increased adherence among users of combination therapies with positive financial impact on both prescription and total medical costs. ${ }^{10-13}$ Nevertheless, many of these studies were conducted among western countries involving patients of White or Black ethnicity. Few studies have investigated the antihypertensive adherence profile among Chinese patients, which constituted more than one-fifth of the world's population residing in different parts of the globe. ${ }^{14}$ As cultural factors including different perceptions and beliefs toward antihypertensive medications could affect drug-taking behavior, ${ }^{15-17}$ it is unknown whether current knowledge on antihypertensive drug persistence could be generalized to patients of Chinese race. Although we recently reported discontinuation profiles of antihypertensive drugs among Chinese patients with ${ }^{18}$ and without concomitant comorbidities, ${ }^{19}$ persistence profiles in patients prescribed combination therapies remained unexplored.

The objectives of this study were to evaluate the discontinuation rates among Chinese patients who received a combination therapy, and investigate the factors associated with drug discontinuation. We tested the hypothesis that age, gender, and the number of comorbidities were significantly associated with discontinuation of combination therapies, as reported in other studies involving Caucasian patients. ${ }^{20-25}$

\section{METHODS}

Source of data

A detailed description of the dataset has been described elsewhere. ${ }^{19}$ Briefly, we utilized a comprehensive computerized patient recording system of the Hospital Authority, Hong Kong. It consists of patients' clinical and demographic parameters, clinical diagnoses in terms of the International Classification of Primary Care-2 (ICPC-2) codes, types of clinical services 
(general out-patient (GOPC) vs. family medicine specialist clinic (FMSC) vs. staff clinics), as well as drug prescription details. There are 7 million patient records, 1 million annual admissions and 13 million ambulatory visits in the database. Research is one of its objectives. ${ }^{26}$ Our previous study indicated a high level of data completeness on demographic (100\%) and prescription details $(99.98 \%)^{27}$

There are several features that enhances the validity of the computerized database:

(1) For each clinic visit, patients should register at first attendance with their official identity documents. Administrative staff in the reception office entered their demographic and socioeconomic data into the computer system.

(2) The attending physicians enter the prescription information into the computer system, which are checked at least twice by staff in the dispensary. Each prescription involves at least two independent dispensers or pharmacists for accurate drug dispensing.

(3) The computerized system is the only means for issuing drug prescriptions, including private medications. All amendments to drug prescriptions by physicians are also documented into the computer system.

(4) These computer recording systems are the only means of information entry by physicians at each patient consultation in all primary care clinics. Clinical guidelines indicate that every physician should enter the clinical diagnoses in the form of ICPC-2 codes for every consultation.

The data sources of this study include patient information from the New Territory East cluster (NTE) of Hong Kong (one out of its seven clusters), providing primary healthcare services to approximately 1.3 million residents, or to $17.2 \%$ of the Hong Kong population. ${ }^{28}$ These records allow cross-referencing by physicians when patients visit a different clinic in other regions. The NTE is further divided into three distinct geographical regions, namely Shatin, Taipo and North district, from the most urbanized to the least, respectively. Their median monthly household incomes in 2006 were US\$2510, US\$2338 and US $\$ 2078$ for these three regions, respectively, which is comparable to the Hong Kong-wide figure of US $\$ 2240 .{ }^{28}$ These three regions have median ages of 38-39 years compared with the median age of 39 years for Hong Kong. The Survey and Research Behavioural Ethics Committee, Chinese University of Hong Kong approved this study. Informed consent was not needed as we anonymized all patients and replaced each patient's name by the numbers of their identity documents, which were unique.

\section{Definition of the cohort}

All adult patients 18 years or older who have attended a primary care clinic at least once and were prescribed a combination therapy during the study period January 2004 to June 2007 were eligible. Each patient was assigned the number of comorbidities according to the total number of concomitant cardiovascular disorders (for example, diabetes mellitus, lipid disorders, cerebrovacular diseases), diseases that were compelling indications or contraindications of a particular class of antihypertensive drug (for example, asthma, gout, chronic bronchitis), or medical conditions that could potentially confound the prescription choice of antihypertensive agents (for example, heart failure, glomerulonephritis) since the calendar year 2000. Table 1 shows a complete list of these diseases by their ICPC- 2 codes.

Each patient was represented only once in the study. In case of multiple visits during the study period, only the earliest visit was included. Blood pressure was measured by an automated calibrated blood pressure machine after patients had had adequate rest for at least $10 \mathrm{~min}$.

\section{Exposure to drugs and assessment of persistence}

We defined drug discontinuation as the absence of refill prescription in all subsequent clinic visits without issuance of any antihypertensive drug in the subsequent 180 days since the first prescription date. This definition is similar to prior studies, ${ }^{29,30}$ except that we used a longer time frame of 180 days (instead of 90 days), as the practice of prescribing antihypertensive drugs in our database is variable, ranging from a period of 14 to 168 days (median 56 days).
Table 1 Comorbidities according to the respective International Classification of Primary Care (ICPC) code

\begin{tabular}{ll}
\hline ICPC code & Disease entity \\
\hline T90 & Diabetes mellitus \\
T901 & Impaired glucose tolerance \\
T92 & Gout \\
T93 & Lipid disorders \\
K90 & Stroke/cerebrovascular accident \\
K91 & Cerebrovascular disease \\
K74 & Ischemic heart disease with angina \\
K76 & Ischemic heart disease without angina \\
K75 & Acute myocardial infarction \\
K77 & Heart failure \\
K84 & Heart disease, other \\
K99 & Cardiovascular disease, other \\
R79 & Chronic bronchitis \\
R95 & Chronic obstructive pulmonary disease \\
R96 & Asthma \\
U14 & Kidney symptoms/complaints \\
U88 & Glomerulonephritis/nephrosis \\
Y85 & Benign prostatic hypertrophy \\
U78 & Benign neoplasm urinary tract \\
Y79 & Benign/unspecified neoplasm, male genital \\
\end{tabular}

\section{Major variables and statistical analysis}

The crude rate of drug discontinuation was compared among different patient groups by chi square tests of independence. The major outcome variable was the 180-day discontinuation rate. The variables tested for association with the outcome included patients' age ( $<50$ years; $50-69$ years; $60-69$ years; $\geqslant 70$ years), gender (male vs. female), payment status (fee-waivers vs. fee-payers), service types (GOPC vs. FMSC vs. staff clinics), districts of residence (Shatin $v s$. Taipo $v s$. North district $v s$. others), visit type (new $v s$. subsequent visit), calendar years of drug prescription, and the total number of comorbidities as reflected by the number of ICPC codes. Fee waivers refer to residents receiving public social security allowances. A medical social worker will determine their inability to pay for medical consultation fee in order to qualify for fee waiving, and this process is comprehensively assessed. Including investigation and prescription fees, each consultation costs US\$5.77. New users were defined as those who had never been prescribed antihypertensive medications since the calendar year 2000 in these primary care clinics as shown in the electronic computer system.

We conducted one binary logistic regression analysis including all patients with a drug discontinuation rate within 180 days as the outcome variable. Patients were subsequently stratified into different age $(<50,50-69, \geqslant 70$ years) and gender (male and female) groups and identical regression analyses were re-conducted to evaluate any differences in the associated factors among these sub-groups of patients. Although selection of independent variables was hypothesis-driven, all the potentially independent variables were entered into the regression equations unconditionally. All $P$ values $\leqslant 0.05$ were regarded as statistically significant. We used the Statistical Package for Social Sciences (SPSS Incorporation, IL, USA) version 15.0.

\section{RESULTS}

\section{Patient characteristics}

From a total of 29253 eligible patients with an average age of 62.9 years (95\% confidence interval [CI] 62.7-63.1 years), 67.4\% were aged 60 years or older (Table 2). A total of $55.3 \%$ were female, $75.0 \%$ fee payers, and almost $90 \%$ visited general out-patient clinic; $70.7 \%$ lived in more urbanized districts (Shatin and Taipo). There were $47.8 \%$ new visitors, and most had uncomplicated hypertension as their only medical condition $(68.8 \%)$. The majority of the prescriptions were issued in the calendar year 2004 (Table 2). There was an average of 2.2 visits during the 180-day period. The prescriptions consisted of 
Table 2 Patient characteristics $(N=29253)$

\begin{tabular}{|c|c|}
\hline & No. (\%) \\
\hline \multicolumn{2}{|l|}{ Age (years) } \\
\hline$<50$ & $3159(10.8)$ \\
\hline $50-59$ & $6351(21.7)$ \\
\hline $60-69$ & 7034 (24.0) \\
\hline$>70$ & $12709(43.4)$ \\
\hline \multicolumn{2}{|l|}{ Gender } \\
\hline Male & $13089(44.7)$ \\
\hline Female & $16164(55.3)$ \\
\hline \multicolumn{2}{|l|}{ Payment status } \\
\hline Fee waivers & $7299(25.0)$ \\
\hline Fee payers & 21954 (75.0) \\
\hline \multicolumn{2}{|l|}{ Service types } \\
\hline GOPC & $26108(89.2)$ \\
\hline FMSC & 3104 (10.6) \\
\hline Staff clinics & $41(0.1)$ \\
\hline \multicolumn{2}{|c|}{ District of residence } \\
\hline Shatin & $13884(47.5)$ \\
\hline Taipo & $6785(23.2)$ \\
\hline North & $6290(21.5)$ \\
\hline Others & $2294(7.8)$ \\
\hline \multicolumn{2}{|l|}{ Visit type } \\
\hline New & $13995(47.8)$ \\
\hline Subsequent & $15258(52.2)$ \\
\hline \multicolumn{2}{|l|}{ Comorbidities } \\
\hline 0 & 20117 (68.8) \\
\hline 1 & $7488(25.6)$ \\
\hline$>2$ & $1648(5.6)$ \\
\hline \multicolumn{2}{|c|}{ Calendar years of prescription } \\
\hline 2004 & 21595 (73.8) \\
\hline 2005 & 4198 (14.4) \\
\hline 2006 & $2418(8.3)$ \\
\hline 2007 & $1042(3.6)$ \\
\hline
\end{tabular}

Abbreviations: FMSC, family medicine specialist clinic; GOPC, general out-patient clinics. All the percentages are across columns.

triamterine/hydrochlorothiazide (15.4\%), amiloride/hydrochlorothiazide $(84.4 \%)$, irebesartan/hydrochlorothiazide $(0.01 \%)$, and losartan/ hydrochlorothiazide $(0.15 \%)$.

\section{Profiles of drug discontinuers vs. adherers}

There were 2063 patients (7.1\%) who have discontinued their drug prescriptions within 180 days (Table 3 ). When compared with drug adherers, the discontinuers were younger $(<60$ years; $35.7 \%$ vs. $32.3 \%, P<0.001)$, more were male patients $(50.9 \%$ vs. $44.3 \%$, $P<0.001)$, fee waivers $(26.7 \%$ vs. $24.8 \%, P=0.063)$, attendees of family medicine specialist clinic or staff clinics $(16.5 \%$ vs. $10.3 \%$, $P<0.001)$, new visitors $(71.4 \%$ vs. $46.1 \%, P<0.001)$ and had no concomitant comorbidities $(77.8 \%$ vs. $68.1 \%, P<0.001$, see Table 3$)$.

Factors associated with antihypertensive discontinuation

When drug discontinuation within 180 days after their first prescription was used as a binary outcome variable in multivariate regression
Table 3 Characteristics of discontinuers vs. adherers $(N=29253)$

\begin{tabular}{|c|c|c|c|}
\hline & $\begin{array}{c}\text { Discontinuers }(\mathrm{n}=2063) \\
\text { No. }(\%)\end{array}$ & $\begin{array}{c}\text { Adherers }(\mathrm{n}=27190) \\
\text { No. (\%) }\end{array}$ & $\mathrm{P}$ \\
\hline \multicolumn{4}{|l|}{ Age (years) } \\
\hline$<50$ & $301(14.6)$ & $2858(10.5)$ & $<0.001$ \\
\hline $50-59$ & $436(21.1)$ & 5915 (21.8) & \\
\hline $60-69$ & 408 (19.8) & $6626(24.4)$ & \\
\hline$>70$ & $918(44.5)$ & $11791(43.4)$ & \\
\hline \multicolumn{4}{|l|}{ Gender } \\
\hline Male & 1051 (50.9) & $12038(44.3)$ & $<0.001$ \\
\hline Female & 1012 (49.1) & $15152(55.7)$ & \\
\hline \multicolumn{4}{|l|}{ Payment status } \\
\hline Fee waivers & $550(26.7)$ & $6749(24.8)$ & 0.063 \\
\hline Fee payers & $1513(73.3)$ & $20441(75.2)$ & \\
\hline \multicolumn{4}{|l|}{ Service types } \\
\hline GOPC & $1721(83.4)$ & 24387 (89.7) & $<0.001$ \\
\hline FMSC & $333(16.1)$ & $2771(10.2)$ & \\
\hline Staff clinics & $9(0.4)$ & $32(0.1)$ & \\
\hline \multicolumn{4}{|c|}{ District of residence } \\
\hline Shatin & $976(47.3)$ & 12908 (47.5) & $<0.001$ \\
\hline Taipo & $380(18.4)$ & 6405 (23.6) & \\
\hline North & 402 (19.5) & $5888(21.7)$ & \\
\hline Others & $305(14.8)$ & $1989(7.3)$ & \\
\hline \multicolumn{4}{|l|}{ Visit type } \\
\hline New & $1474(71.4)$ & $12521(46.1)$ & $<0.001$ \\
\hline Subsequent & 589 (28.6) & 14669 (53.9) & \\
\hline \multicolumn{4}{|l|}{ Comorbidities } \\
\hline 0 & 1605 (77.8) & $18512(68.1)$ & $<0.001$ \\
\hline 1 & $374(18.1)$ & $7114(26.2)$ & \\
\hline 2 & $84(4.1)$ & $1564(5.8)$ & \\
\hline \multicolumn{4}{|c|}{ Calendar years of prescription } \\
\hline 2004 & 779 (37.8) & $20816(76.6)$ & $<0.001$ \\
\hline 2005 & $553(26.8)$ & $3645(13.4)$ & \\
\hline 2006 & $311(15.1)$ & $2107(7.7)$ & \\
\hline 2007 & $420(20.4)$ & $622(2.3)$ & \\
\hline
\end{tabular}

Abbreviations: FMSC, family medicine specialist clinic; GOPC, general out-patient clinics. All the percentages are across columns.

analysis, younger patients ( $<50$ years) were more likely to have their drugs discontinued (adjusted odds ratios [aOR]: 0.78, 95\% CI: 0.66$0.92, P=0.003$ for $50-59$ years; aOR: $0.71,95 \%$ CI: $0.60-0.84$, $P<0.001$ for $60-69$ years). Male patients were significantly more likely than their female counterparts to be drug discontinuers (aOR: 1.19, 95\% CI: $1.08-1.31, P<0.001)$. When compared with patients having no comorbidity, subjects with one (aOR: 0.64, 95\% CI: $0.57-$ $0.73, P<0.001$ ) and at least two comorbidities (aOR: $0.68,95 \% \mathrm{CI}$ : $0.54-0.87, P=0.002)$ were significantly less likely to have their drugs discontinued (Table 4). Another significant finding was the remarkably lower discontinuation rate among follow-up visitors (3.9\%; aOR: $0.51,95 \%$ CI: $0.46-0.56, P<0.001)$ than new visitors $(10.5 \%)$.

\section{Sensitivity analyses}

As sensitivity analyses, when all patients were stratified into different age $(<50,50-69, \geqslant 70$ years) and gender groups (male vs. female) 
Table 4 Factors associated with antihypertensive discontinuation 180 days after the first date of prescription $\left(N=29253, r^{2}=0.21\right)$

\begin{tabular}{|c|c|c|c|c|}
\hline & $\mathrm{n}$ & $\%$ & Adjusted OR (95\% C.I) & $\mathrm{P}$ \\
\hline \multicolumn{5}{|l|}{ Age (years) } \\
\hline$<50$ & 301 & 9.5 & 1.00 (reference) & \\
\hline $50-59$ & 436 & 6.9 & $0.78(0.66-0.92)$ & 0.003 \\
\hline $60-69$ & 408 & 5.8 & $0.71(0.60-0.84)$ & $<0.001$ \\
\hline$>70$ & 918 & 7.2 & $0.90(0.77-1.04)$ & 0.159 \\
\hline \multicolumn{5}{|l|}{ Gender } \\
\hline Female & 1051 & 6.5 & 1.00 (reference) & \\
\hline Male & 1012 & 7.7 & $1.19(1.08-1.31)$ & $<0.001$ \\
\hline \multicolumn{5}{|l|}{ Payment status } \\
\hline Fee waivers & 550 & 7.5 & 1.00 (reference) & \\
\hline Fee payers & 1513 & 6.9 & $0.90(0.81-1.00)$ & 0.059 \\
\hline \multicolumn{5}{|l|}{ Service types } \\
\hline GOPC & 1721 & 6.6 & 1.00 (reference) & \\
\hline FMSC & 333 & 10.7 & $1.73(1.49-2.00)$ & $<0.001$ \\
\hline Staff clinics & 9 & 22.0 & $2.07(0.92-4.67)$ & 0.078 \\
\hline \multicolumn{5}{|c|}{ District of residence } \\
\hline Shatin & 976 & 7.0 & 1.00 (reference) & \\
\hline Taipo & 380 & 5.6 & $1.08(0.94-1.23)$ & 0.291 \\
\hline North & 402 & 6.4 & $0.96(0.84-1.10)$ & 0.561 \\
\hline Others & 305 & 13.3 & $1.95(1.68-2.26)$ & $<0.001$ \\
\hline \multicolumn{5}{|l|}{ Visit type } \\
\hline New & 1474 & 10.5 & 1.00 (reference) & \\
\hline Subsequent & 589 & 3.9 & $0.51(0.46-0.56)$ & $<0.001$ \\
\hline \multicolumn{5}{|l|}{ Comorbidities } \\
\hline 0 & 1605 & 8.0 & 1.00 (reference) & \\
\hline 1 & 374 & 5.0 & $0.64(0.57-0.73)$ & $<0.001$ \\
\hline$>2$ & 84 & 5.1 & $0.68(0.54-0.87)$ & 0.002 \\
\hline
\end{tabular}

Abbreviations: $\mathrm{Cl}$, confidence interval; FMSC, family medicine specialist clinic; GOPC, general out-patient clinics; OR, odd ratios.

All the percentages represent the proportion of patients who discontinued their medications 180 days within the first date of drug prescription and are across rows.

followed by similar regression analyses for each group, the associated factors identified in Table 4 remained statistically and similarly significant. In addition, when we extended the discontinuation period from 180 to 270 days and 360 days, respectively, and identical regression analyses were conducted, these associated factors remained the same (results not shown).

All the covariates were tested for multicollineraity $(r>0.8$ between any two variables) to ensure robustness of the regression analysis and we reported no significant correlations among all variables. The nagelkerke $R^{2}$ was 0.21 , implying that all the independent variables in the regression analysis accounted for $21 \%$ of the variability of the outcome variable.

\section{DISCUSSION}

From 29253 Chinese patients prescribed an antihypertensive medication, the drug discontinuation rate within 180 days was $7.1 \%$ overall and $10.5 \%$ for patients who prescribed their first-ever antihypertensive drugs. Young age, male gender, new visits, and the absence of comorbidities were independently associated with drug discontinuation.
Our findings revealed a lower discontinuation rate of combination therapies 180 days after their prescriptions, when compared with our earlier studies on the discontinuation incidences of the major antihypertensive drug classes within the same time frame. ${ }^{18,19}$ The $\beta$-blockers had the highest discontinuation rate $(20.8 \%)$, followed by angiotensin-converting enzyme inhibitors (14.0\%), thiazide diuretics $(12.5 \%)$, and calcium channel blockers $(9.7 \%) .{ }^{19}$ This could be due to the packaging of the fixed-dose components in doses lower than that in monotherapy, leading to reduced incidences of doserelated side effects.

In addition, the finding of discontinuation rate of $7.1 \%$ at 180 days was much lower than that reported by the National Managed Care Benchmark Database (27\% among 8150 patients prescribed a combination therapy). ${ }^{10} \mathrm{~A}$ recent study using the US pharmacy benefits manager found a discontinuation rate of approximately 50\% at 365 days. ${ }^{31}$ Other similar observational studies also reported high incidences of drug discontinuation ${ }^{31-40}$ among Caucasian hypertensive patients. The potential explanations might include better tolerability profiles of combination therapies among Chinese patients, as well as the higher convenience and simpler dosing schedules of combination therapies as perceived by the Chinese culture. Our study is so far the first in the Asia-Pacific region showing a substantially lower discontinuation rate among patients prescribed combination therapies, which bears significant health service implications as they could be favorable options as an antihypertensive pharmacotherapy of choice for Chinese patients.

Young age has earlier been shown as a positive factor associated with drug discontinuation..$^{20-23}$ Our findings showed that this was not only the case for the major antihypertensive drug classes, but this also applied to users of combination therapies. As the major reason of drug discontinuation could be medication side effects, younger patients might be more intolerant to combination therapies; alternatively, young hypertensives could be less vigilant toward the importance of regular medication taking because of their lower risk of cardiovascular diseases. The exact reasons remained to be explored.

We also showed that male patients were more likely to be drug discontinuers similar to findings from western countries. ${ }^{20,24}$ However, the absolute difference between the two genders was clinically small $(1.2 \%)$, possibly because of convenience of using fixed-dose combination therapies. ${ }^{41}$ As male constitutes the major working population in highly industrialized Asian regions such as Hong Kong, they were less likely to be regular clinic attendees.

Our findings that patients with concomitant morbidities had lower likelihood of drug discontinuation were compatible with Caucasian studies showing better antihypertensive adherence among patients having multiple chronic conditions. ${ }^{20,24,25}$ It has been suggested that the health belief model fits in the explanation, in which patients perceiving themselves to be sicker tend to comply better to physicians' management. ${ }^{22}$

The strengths and limitations of this study have been described elsewhere. ${ }^{19}$ Our study is a large evaluation conducted in the Chinese population on the discontinuation profiles of combination therapies. One of the strengths of this study is the large sample size generated in a large territory. We collected data on clinical practices not under intervention, which could be more representative of real clinical consultations. The strengths and weaknesses of the electronic database from which this study was drawn have been discussed earlier. ${ }^{42}$ Non-differential information bias might result owing to use of dispensing data only, and we cannot take into account behavior modifications after prescriptions. In addition, there is an assumption that pharmacy refill data were accurate measures of medication-taking 
behavior in reality. However, administrative databases are superior in measuring drug exposure to other data collection methods such as patient interviews or self-administered surveys as recall biases could be eliminated. ${ }^{43}$ This study also included subjects with concomitant cardiovascular disorders, which allows analysis of patients having different comorbidity statuses.

Our patients were recruited from one region of Hong Kong, although similar patterns of prescribing to those found in the present study have been observed in earlier smaller studies in other regions of Hong Kong, ${ }^{44-46}$ thus enhancing the generalizability of our study findings to other primary care settings. Uncomplicated hypertension is one of the most commonly encountered conditions seen in primary care clinics in the public healthcare sector in Hong Kong, and a substantial majority of the population attends the public health services instead of the private sector for management of hypertension. Our findings could be of importance at the public health level in terms of management of hypertension.

The regression models accounted for part of the outcome variables (goodness of fit $r^{2}=0.21$ ), and there were factors that could not be controlled in database studies, such as the reasons for drug discontinuation. In addition, we did not take into account the defined daily dose of drug prescription and the number of clinic visits in the regression analyses. It is more desirable to use an inception cohort as a better design simulating prospective trials, and this study analyzed both new and follow-up clinic attendees.

In conclusion the factors associated with discontinuation of combination therapies among Chinese patients were evaluated in this study, and we found that the discontinuation rate was low 180 days after their prescriptions. Among patients with these associated factors, doctors and allied health professionals should consider monitoring their compliance profiles more closely during clinic consultations. The involvement of team members from different disciplines ${ }^{47}$ should also be strengthened to enhance patient compliance.

As far as we are aware, our study is the largest evaluation ever conducted in the Asia-Pacific region on the discontinuation profiles of combination therapies in patients treated in primary care. The major strength of our study is, therefore, the robust sample size generated over a 3.5-year period. Besides, we captured data in clinical practices not under research settings, allowing the findings to be more reflective of 'real-life practice'. The strengths and weaknesses of the electronic database from which this study was drawn have been discussed earlier. ${ }^{42}$ The use of dispensing data instead of drug administration may lead to non-differential information bias, and cannot take into account lifestyle changes after prescriptions. In addition, we assumed that pharmacy refill data were accurate measures of real medicationtaking behavior. Nevertheless, administrative databases have many advantages to measure drug exposure when compared with other data collection methods such as interviews or self-administered surveys as the latter could induce recall biases. ${ }^{43}$ In this study, we also included patients with concomitant cardiovascular diseases and coded conditions that might influence the choice of antihypertensive agent prescribed, allowing analysis in a wider spectrum of hypertensive patients with different comorbidity profiles.

Our sample is from the Hospital Authority responsible for only one territory of Hong Kong. However, similar patterns of prescribing to those found in this study have been reported in earlier smaller studies in other clusters of Hong Kong ${ }^{44-46}$ and thus it is likely that our findings are generalizable in terms of primary care within the public healthcare system in Hong Kong. We cannot extrapolate our findings to the private healthcare sector. Nevertheless, uncomplicated hypertension is the second most common condition seen in primary care clinics in the public healthcare sector in Hong Kong, and available data suggests that the majority of the population attends the public health services rather than the private sector for management of hypertension. Thus, our findings may well be of significance at population level in terms of hypertension management and healthcare costs.

The regression models were far from complete as reflected by the goodness of fit $\left(r^{2}=0.21\right)$, and there were covariables, which could not be taken into account in database studies, such as the reasons of drug discontinuation. In addition, we did not take into account the mean dose of drug prescription and the number of clinic visits into the regression analyses. In addition, it was recognized that the use of inception cohort is a better design simulating the situation of a randomized controlled trial, in which this study analyzed both new and follow-up patients.

In summary, this study has evaluated the factors associated with discontinuation of combination therapies among ethnic Chinese and its discontinuation rate was low 180 days after their prescriptions. Major stakeholders of the primary care team including physicians and pharmacists should consider to prescribe fixed-dose combination therapy especially among those who are likely to be poor adherers.

From a health-system point of view, it raises the need to implement more innovative and realistic chronic disease models of disease management among those likely to be discontinuers. This consists of patient-professional partnership, multidisciplinary team approach, self-management education, clinical information systems, and development of decision support and clinical indicators, ${ }^{47}$ so that patient adherence to combination therapies could be further enhanced.

\section{CONFLICT OF INTEREST}

The authors declare no conflict of interest.

\section{ACKNOWLEDGEMENTS}

We thank the Hospital Authority and the primary care research group of the School of Public Health, Chinese University of Hong Kong for their expert input.

1 Psaty BM, Lumsley T, Furberg CD, Schellenbaum G, Pahor M, Alderman MH, Weiss NS Health outcomes associated with various antihypertensive therapies used as first-line agents: a network meta-analysis. JAMA 2003; 289: 2534-2544.

2 McCombs JS, Nichol MB, Newman CM, Sclar DA. The costs of interrupting antihypertensive drug therapy in a Medicaid population. Med Care 1994; 32: 214-226.

3 Sokol MC, McGuigan KA, Verbrugge RR, Epstein RS. Impact of medication adherence on hospitalization risk and healthcare cost. Med Care 2005; 43: 521-530.

4 Rizzo JA, Simons WR. Variations in compliance among hypertensive patients by drug class: implications for health care costs. Clin Ther 1997; 19: 1446-1457.

5 Caro JJ, Speckman JL. Existing treatment strategies: does noncompliance make a difference? J Hypertens 1998; 12: S533-S537.

6 Mazzaglia G, Ambrosioni E, Alacqua M, Filippi A, Sessa E, Immordino V, Borghi C, Brignoli O, Caputi AP, Cricelli C, Mantovani LG. Adherence to antihypertensive medications and cardiovascular morbidity among newly diagnosed hypertensive patients. Circulation 2009; 120: 1598-1605.

7 Wolf-Maier K, Cooper RS, Banegas JR, Giampaoli S, Hense HW, Joffres M, Kastarinen M, Poulter N, Primatesta P, Rodríguez-Artalejo F, Stegmayr B, Thamm M, Tuomilehto J, Vanuzzo D, Vescio F. Hypertension prevalence and blood pressure levels in 6 European countries, Canada and the United States. JAMA 2003; 289: 2363-2369.

8 Wetzels GE, Nelemans P, Schouten JS, Prins MH. Facts and fiction of poor compliance as a cause of inadequate blood pressure control: a systematic review. J Hypertens 2004; 22: 1849-1855.

9 Sica DA. Rationale for fixed-dose combination in the treatment of hypertension: the cycle repeats. Drugs 2002; 62: 443-462.

10 Brixner DI, Jackson II KC, Sheng X, Nelson RE, Keskinasian A. Assessment of adherence, persistence, and costs among valsartan and hydrochlorothiazide: retrospective cohorts in free- and fixed-dose combinations. Curr Med Res Opin 2008; 24: 2597-2607.

11 Law MR, Wald NJ, Morris JK, Jordan RE. Value of low dose combination treatment with blood pressure lowering drugs: analysis of 354 randomised trials. BMJ 2003; 326: 1427-1434. 
12 Van Wijk BL, Klungel OH, Heerdink ER, de Boer A. Rate and determinants of 10-year persistence with antihypertensive drugs. J Hypertens 2005; 23: 2101-2107.

13 Perreault S, Lamarre D, Blais L, Dragomir A, Berbiche D, Lalonde L, Laurier C, St-Maurice F, Collin J. Persistence with treatment in newly treated middle-aged patients with essential hypertension. Ann Pharmacother 2005; 39: 1401-1408.

14 World Health Organization. Country Health Information Profiles. Available at: http:// www.wpro.who.int/NR/rdonlyres/E3A15481-80E2-400B-B801-B52AC6F0C790/0/ 9finalCHNpro09.pdf. Accessed on 11 December 2009.

15 Ogedegbe G, Mancuso CA, Allegrante JP, Charlson ME. Development and evaluation of a medication adherence self-efficacy scale in hypertensive African-American patients. J Clin Epidemiol 2003; 56: 520-529.

16 Ogedegbe G, Harrison M, Robbins L, Mancuso CA, Allegrante JP. Barriers and facilitators of medication adherence in hypertensive African Americans: a qualitative study. Ethn Dis 2004; 14: 3-12.

17 van Wijk BLG, Shrank WH, Klungel OH, Schneeweiss S, Brookhart MA, Avorn J. A cross-national study of the persistence of antihypertensive medication use in the elderly. J Hypertensi 2008; 26: 145-153.

18 Wong MCS, Jiang JY, Lam A, Fung H, Griffiths S, Mercer SW. Patterns of antihypertensive prescribing, discontinuation and switching among a Hong Kong Chinese population from over one million prescriptions. J Hum Hypertens 2008; 22: 714-716.

19 Wong MCS, Jiang JY, Gibbs T, Griffiths SM. Factors associated with antihypertensive drug discontinuation among Chinese patients: a cohort study. Am J Hypertens 2009; 22: $802-810$.

20 Caro JJ, Salas M, Speckman JL, Raggio G, Jackson JD. Persistence with treatment for hypertension in actual practice. CMAJ 1999; 160: 31-37.

21 Degli Eposti L, Degli Eposti E, Valpiani G, Di Martino M, Saragoni S, Buda S, Baio G, Capone A, Sturani A. A retrospective, population-based analysis of persistence with antihypertensive drug therapy in primary care practice in Italy. Clin Ther 2002; 24: 1347-1357.

22 Billups SJ, Malone DC, Carter BL. The relationship between drug therapy noncompliance and patient characteristics, health-related quality of life, and health care costs. Pharmacotherapy 2000; 20: 941-949.

23 Vaur L, Vaisse B, Genes N, Elkik F, Legrand C, Poggi L. Use of electronic pill boxes to assess risk of poor treatment compliance: results of a large-scale trial. Am J Hypertens 1999; 12: 374-380.

24 Flack JM, Novikov SV, Ferrario CM. Benefits of adherence to antihypertensive drug therapy. Eur Heart J 1996; 17: 16-20.

25 Knight EL, Bohn RL, Wang PS, Glynn RJ, Mogun H, Avorn J. Predictors of uncontrolled hypertension in ambulatory patients. Hypertension 2001; 38: 809-814.

$26 \mathrm{HA}$ and clinical research. Support, Output and Direction. Available at http://www.ha.org.hk/ho/research_ethics/msdc_p181.pdf. Accessed on 04 December 2009.

27 Wong MCS, Jiang JY, Tang JL, Lam A, Fung H, Mercer SW. Health services research in the public healthcare system in Hong Kong: an analysis of over 1 million antihypertensive prescriptions between 2004-2007 as an example of the potential and pitfalls of using routinely collected electronic patient data. BMC Health Ser Res 2008; 8 : 138. Available at: http://www.ncbi.nlm.nih.gov/pmc/articles/PMC2453117/pdf/14726963-8-138.pdf. Accessed on 04 Dec 2009.

28 Population by-census, 2006. Hong Kong Special Administrative Region, China. Available at: http://www.bycensus2006.gov.hk/en/data/data3/index.htm. Accessed on 04 December 2009.

29 Burke TA, Sturkenboom MC, Lu S, Wenworth CE, Lin Y, Rhoads GG. Discontinuation of antihypertensive drugs among newly diagnosed hypertensive patients in UK general practice. J Hypertens 2006; 24: 1193-1200.
30 Mazzaglia G, Mantovani LG, Sturkenboom MCJM, Filippi A, Trifiro G, Cricelli C, Brignoli O, Caputi AP. Patterns of persistence with antihypertensive medications in newly diagnosed hypertensive patients in Italy: a retrospective cohort study in primary care. J Hypertens 2005; 23: 2093-2100.

31 Jones JK, Gorkin L, Lian JF, Staffa JA, Fletcher AP. Discontinuation of and changes in treatment after start of new courses of antihypertensive drugs: a study of United Kingdom population. BMJ 1995; 311: 293-295.

32 Bloom BS. Continuation of initial antihypertensive medication after 1 year of therapy. Clin Ther 1998; 20: 671-681.

33 Bourgault C, Senecal M, Brisson M, Marentette MA, Gregoire J-P. Persistence and discontinuation patterns of antihypertensive therapy among newly treated patients: a population-based study. J Hum Hypertens 2005; 19: 607-613.

34 Caro JJ, Speckman JL, Salas M, Raggio G, Jackson JD. Effect of initial drug choice on persistence with antihypertensive therapy: the importance of actual practice data. Can Med Assoc J 1999; 160: 41-46.

35 Degli Esposti L, Degli Esposti E, Valpiani G, Di Martino M, Saragoni S, Buda S, Baio G, Capone A, Sturani A. A retrospective, population-based analysis of persistence with antihypertensive drug therapy in primary care practice in Italy. Clin Ther 2002; 24: 1347-1357.

36 Degli Esposti E, Sturani A, Di Martino M, Falasca P, Novi MV, Baio G, Buda S, Volpe M. Long-term persistence with antihypertensive drugs in new patients. J Hum Hypertens 2002; 16: 439-444.

37 Conlin PR, Gerth WC, Fox J, Roehm JB, Boccuzzi SJ. Four-year persistence patterns among patients initiating therapy with the angiotensin II receptor antagonist losartan versus other antihypertensive drug classes. Clin Ther 2001; 23: 1999-2010.

38 Hasford J, Mimran A, Simons WR. A population-based European cohort study of persistence in newly diagnosed hypertensive patients. J Hum Hypertens 2002; 16 : 569-575.

39 Erkins JA, Panneman MM, Klungel OH, van den Boom G, Prescott MF, Herings RM. Differences in antihypertensive drug persistence associated with drug class and gender: a PHARMO study. Pharmacoepidemiol Drug Saf 2005; 14: 795-803.

40 Van Wijk BLG, Klungel OH, Heerdink ER, de Boer A. Rate and determinants of 10-year persistence with antihypertensive drugs. J Hypertens 2005; 23: 2101-2107.

41 Woodham RM, Oparil S. Fixed low-dose antihypertensive therapy. In: Lip GYH, Hall JE (eds). Comprehensive Hypertension. Mosby, Philadelphia, 2007, 1061-1073.

42 Halpern MT, Khan ZM, Schmier JK, Burnier M, Caro JJ, Cramer J, Daley WL, Gurwitz J, Hollenberg NK. Recommendations for evaluating compliance and persistence with hypertension therapy using retrospective data. Hypertension 2006; 47: 1039-1048

43 Grymonpre RE, Didur CD, Montgomery PR, Sitar DS. Pill count, self-report, and pharmacy claims data to measure medication adherence in the elderly. Ann Pharmacother 1998; 32: 749-754.

44 Chang S, Chan WH, Kong Y, Chan GM, Raymond K, Lee A, Lee SC, Critchley JA, Chan JC. Use of indapamide in hospital and community clinics and its effect on plasma potassium in Chinese patients. J Clin Pharm Ther 1998; 23: 295-302.

45 Yuen YH, Chang S, Chong CK, Lee SC, Critchley JA, Chan JC. Drug utilization in a hospital general medical outpatient clinic with particular reference to antihypertensive and antidiabetic drugs. J Clin Pharm Ther 1998; 23: 287-294.

46 Cheung BM, Wong YL, Lau CP. Queen Mary Utilization of Antihypertensive Drugs Study: use of antihypertensive drug classes in the hypertension clinic 1996-2004. Br J Clin Pharmacol 2005; 60: 90-97.

47 Carter BL. Adherence, quality of life, cost effectiveness, and the role of the pharmacist. In: Lip GYH, Hall JE (eds). Comprehensive Hypertension. Mosby, Philadelphia, 2007, 1119-1127. 